\title{
DISLEXIA NO ESPAÇO ESCOLAR: DIFICULDADE DURADOURA NA APRENDIZAGEM DA LEITURA
}

CLAUDIA BARRETO DOS SANTOS SATURNINO ${ }^{1}$

ROSEMEIRE DE ASSIS BORGES SANTOS ${ }^{2}$

\begin{abstract}
RESUMO
O presente artigo tem como objetivo compreender como se constitui a dislexia, como incapacidade do cérebro na organização do disléxico que provoca um déficit no desenvolvimento do reconhecimento e compreensão de ler certos escritos, assim como na leitura. Espera-se com a realização desse trabalho contribuir para educação brasileira para a superação dos transtornos relacionados a dislexia, de modo que venha a divulgar as elucidações que estão presentes no segmento educacional, e, debatendo os sintomas, causas, diagnósticos e as possibilidades de intervenções por profissionais.
\end{abstract}

Palavras-chave: Dislexia; Aprendizagem; Diagnóstico; Tratamento.

\section{INTRODUÇÃO}

Há uma enorme preocupação quando se trata do tema dislexia, principalmente relacionados às crianças que estão em processo de alfabetização. As dislexias são problemas na organização do léxico, ou seja, no arquivo cognitivo das características das palavras como semântica, ortográfica e fonológica, que provocam um déficit no desenvolvimento do reconhecimento e compreensão dos textos escritos.

Podem ser observadas como características da dislexia, a leitura lenta, com omissões, distorções e substituições de palavras e, geralmente a compreensão também é afetada (CAPOVILLA; CAPOVILLA, 2000). Essas características estão relacionadas ao funcionamento das rotas de leitura lexical e fonológicas. Sendo que a rota lexical diz respeito ao léxico, ou seja, o arquivo cognitivo das características

\footnotetext{
1 Cláudia Barreto dos Santos Saturnino. Graduada Normal Superior. Pós-graduação em Psicopedagogia: Institucional, clínica e Hospitalar. Especialista em Gestão Educacional.

2 Graduada pela Faculdade de Filosofia, Ciências e Letras de Candeias em Pedagogia. Pósgraduação em Gestão Educacional pela Faculdade Batista Brasileira em Especialização. Pósgraduação em Psicopedagogia Clínica e Institucional pela Faculdade de Artes do Paraná.
} 
da palavra, como semântica e ortografia. Já a rota fonológica é responsável pelo reconhecimento dos sons da língua e pela análise da relação fonema-grafema.

Segundo o neuropsiquiatra americano Orton (1940 apud HOUTE; ESTIENNE, 2001), a dislexia é o resultado de um distúrbio do desenvolvimento que altera o estabelecimento normal da dinâmica hemisférica para a linguagem. De acordo com esse especialista, seria uma alteração da lateralidade hemisférica com implicações na orientação direcional e na memória visual e bruto. No que diz respeito ao tema dislexia, o pesquisador Critchley (1968), considera como um transtorno da aprendizagem da leitura que ocorre, apesar de inteligência normal, da ausência de problemas sensorial e neurológica de uma instrução escolar adequada de oportunidades socioculturais suficientes, além disso, depende de uma perturbação de aptidões cognitivas fundamentais, muitas vezes de origem constitucional.

Para Fonseca (1999) a dislexia é uma dificuldade duradoura na aprendizagem da leitura e aquisição de seu automatismo em crianças normalmente inteligentes, escolarizadas e isentas de distúrbios sensoriais, sendo estimada sua frequência nos Estados Unidos. A dislexia é vista como uma disfunção neurológica de corrente de aspectos funcionais do cérebro onde os autores afirmam que constitui numa dificuldade de aprendizagem e não em uma incapacidade. Pode ser caracterizado também como um problema social, econômico e cultural, uma vez que a aprendizagem da leitura e da escrita deve ser possibilitada a todos as pessoas, independente das suas condições neurológicas.

Segundo Fonseca (1999), a dislexia caracteriza-se por um distúrbio na recepção, integração e expressão da linguagem ou ainda uma dificuldade manifestada no momento em que se dá a aprendizagem da leitura. Esse distúrbio emocional, o meio social e cultural tão pouco influi sobre a ocorrência desse quadro.

Segundo Nunes et al., (2003), aprender a ler e escrever exige novas habilidades, que até então não faziam parte da vida diária da criança. Durante a infância são apresentados novos desafios com relação ao conhecimento da linguagem, o que a torna uma tarefa difícil para todas as crianças. No entanto, algumas mesmo possuindo uma inteligência normal e apresentando ótimas habilidades em outras tarefas, apresentam dificuldades específicas no domínio da leitura e escrita. 
Essa pesquisa que foi realizada durante o Mestrado tem como objetivo compreender como se constitui a dislexia, como incapacidade do cérebro na organização do disléxico que provoca um déficit no desenvolvimento do reconhecimento e compreensão de ler certos escritos e na leitura.

A elaboração desse artigo utilizou aportes da pesquisa bibliográfica, que aproveita discussões de diversos autores que debatem o tema dislexia com intuito de proporcionar aos profissionais de educação e os pais, subsídios para contribuir com o processo de ensino e aprendizagem. Dessa forma, espera-se que através dessas discussões sobre a dislexia possa contribuir com a superação desses transtornos, debatendo questões como os sintomas, causas, diagnósticos e as possibilidades de intervenções por profissionais.

\section{DISLÉXIA: CONCEITO E CARACTERÍSTICAS}

A palavra dislexia é formada pela concentração das palavras gregas dis que significa difícil e lexis cujo significado é a dificuldade na leitura, escrita e soletração. Sendo assim, caracteriza-se por uma dificuldade nas áreas da leitura, escrita e soletração (ALMEIDA, 2010). A dislexia, considerada como um distúrbio de aprendizagem na área da leitura, escrita e soletração, é o transtorno de maior incidência nas salas de aula.

Ao contrário do que muitos pensam a dislexia não é o resultado de uma alfabetização fragilizada, sofrendo com desatenção, desmotivação, condição socioeconômica ou baixa inteligência, nem algo do tipo. A mesma é uma condição inata com alterações genéticas, apresentando ainda alterações no padrão neurológico. E é na escola que a dislexia na maioria das vezes é reconhecida, pois, é o local em que a prática da escrita e leitura é realizada, embora existam disléxicos que revelam suas dificuldades em outros ambientes e situações, como em casa.

De acordo com os documentos oficiais, a educação é um direito de todos e para todos, assim sendo, a escola precisa se adaptar para as necessidades educacionais de seus estudantes como a dislexia, sendo se fundamental importância sua inserção na escola regular.

Conforme a Associação Internacional de Dislexia americana: 
A dislexia é um dos vários tipos de dificuldades de aprendizagem. É uma desordem específica, centrada na linguagem, de origem orgânica, caracterizada por problemas na descodificação de palavras, refletindo, geralmente, capacidades reduzidas no processamento fonológico. Estes problemas na descodificação da palavra são geralmente inesperados ao considerar-se a idade ou as aptidões cognitivas; eles não são o resultado de uma discapacidade desenvolvimental generalizada ou de uma perda sensorial. A dislexia é manifestada por uma dificuldade variável nas diferentes formas da linguagem, incluindo, para além de um problema na leitura, um problema manifesto na aquisição de proficiência na escrita e na soletração.

Portanto, devido a esses vários aspectos apresentados é que a dislexia deve ser diagnosticada por uma equipe multidisciplinar, pois, de acordo com Moojen (2008) "a equipe que trabalha com o disléxico, sejam neurologistas, fonoaudiólogos, psicopedagogos, psicólogos tem que ter uma formação específica nesta área, complementando um sólido conhecimento teórico com uma prática refletida sobre este tema". Esse tipo de diagnóstico oferece condições de um acompanhamento mais concreto das dificuldades enfrentadas pelo estudante, conduzindo às especificidades e particularidades de cada indivíduo, levando a resultados mais eficazes.

Zorzi (2008, p. 8) afirma que:

Outras dificuldades podem ser associadas, como falha de soletração e na ortografia. Com freqüência, os disléxicos exibem uma dificuldade significativa para compreender a estrutura sonora das palavras, ou seja, identificar fonemas separadamente. Também ocorre uma dificuldade para aprender a correspondência entre fonemas e as letras que os representam.

A dislexia, por ser considerada genética e hereditária, quanto mais cedo for diagnosticada na criança por uma equipe multidisciplinar especializada, melhor será o tratamento que trará melhores condições para os pais e a unidade escolar. E esse diagnóstico pode ser realizado observando as seguintes características:

Dificuldades na correção e/ou fluência na leitura de palavras e por baixa competência leitora e ortográfica. Estas dificuldades resultam tipicamente de um défice na componente fonológica da linguagem que é freqüentemente imprevisto em relação a outras capacidades cognitivas e às condições educativas. Secundariamente podem surgir dificuldades de compreensão leitora, experiência de leitura reduzida que podem impedir o desenvolvimento do vocabulário e dos 
conhecimentos gerais. (Associação Internacional de Dislexia, 2003, apud TELES, 2009).

Sabendo-se disso vale ressaltar que quanto mais cedo o diagnóstico melhor, pois, será realizado o acompanhamento e tratamento nos estudantes com especialistas desde cedo, dessa forma, o estudante terá menos dificuldade para estudar e acompanhar seus colegas.

\subsection{Tipos de Dislexia}

Após estudar sobre as características e diagnóstico da dislexia, nesse tópico será discutida a forma como pode ser classificada, sendo elas: a dislexia disfonética, diseidética, visual, auditiva e a mista.

A Dislexia disfonética são as dificuldades de percepção auditiva na análise e síntese de fonemas, dificuldades temporais, e nas percepções da sucessão e da duração (troca de fonemas e grafemas por outros similares, dificuldades no reconhecimento e na leitura de palavras que não têm significado, alterações na ordem das letras e sílabas, omissões e acréscimos, maior dificuldade na escrita do que na leitura, substituição de palavras por sinônimos).

A Dislexia diseitética é a dificuldade na percepção visual, na percepção geostática (percepção do todo como maior que a soma das partes), na análise e síntese de fonemas (ler sílaba por sílaba sem conseguir a síntese das palavras, misturando e fragmentando as palavras, fazendo troca por fonemas similares, com maior dificuldade para a leitura do que para a escrita).

A Dislexia visual é deficiência na percepção visual e na coordenação vasomotora (dificuldade no processamento cognitivo das imagens).

A Dislexia auditiva é a deficiência na percepção auditiva, na memória auditiva e fonética (dificuldade no processamento cognitivo do som das sílabas).

A Dislexia mista que seria a combinação de mais de um tipo de dislexia.

A leitura pode ser considerada como a mais importante no processo de ensino e aprendizagem, sendo o ato de ler o responsável pela aprendizagem de outros saberes. Entretanto, inúmeras pessoas avaliam a leitura como difícil, apresentando assim, um nível médio ou superior de dificuldade na aprendizagem ao tentar aprender esse processo de aprendizagem.

Através da utilização da Ressonância Magnética Funcional foi detectada, nos últimos anos, a forma como o cérebro funciona durante o processo de leitura e 
escrita. Por meio desse procedimento, os neurocientistas puderam tirar suas conclusões de como realmente funciona quando o indivíduo realiza a leitura, o que dificulta essa aprendizagem, dentre outras conclusões.

De acordo com Teles (2004), os Estados Unidos têm sido pioneiros na investigação científica na legislação educativa sobre a dislexia, pois, seus estudos estão relacionados à orientação sobre os métodos de ensino que provaram serem os mais eficientes. O autor discute também que nos anos 60 , sob a influência das corrente psicodinâmicas, foram minimizados os aspectos biológicos da dislexia, atribuindo as dificuldades leitoras a problemas emocionais, afetivos e de maturidade.

\section{DIFICULDADES E TRATAMENTO NO PROCESSO DE APRENDIZAGEM}

O diagnóstico da dislexia na maioria das vezes é realizado pela equipe multidisciplinar como médico, psicólogo, psicopedagogo, fonoaudiólogo e neurologista. Antes de afirmar que uma pessoa é disléxica, é preciso descartar a ocorrência de deficiências visuais e auditivas, déficit de atenção, escolarização inadequada, problemas emocionais, psicológicos e socioeconômicos, ou seja, fatores que possam interferir na aprendizagem.

Segundo Moura (2013):

Os disléxicos recebem informações em uma área diferente do cérebro, portanto o cérebro dos disléxicos é normal. Infelizmente essas informações em áreas diferentes resultam de falhas nas conexões cerebrais. $O$ resultado é que devido a essas falhas no processo de leitura, eles têm dificuldades de aprender a ler, escrever, soletrar, pois é difícil assimilarem as palavras.

lanhez e Nico (2002) apontam sinais importantes de dislexia, onde os sintomas variam de pessoa para pessoa, que são:

Lentidão na aprendizagem dos mecanismos da leitura e escrita;

Trocas ortográficas ocorrem, mas dependem do tipo de dislexia;

Problema para reconhecer fonemas repetidos em uma frase;

Desempenho escolar abaixo da média, em matérias específicas, que dependem da linguagem escrita;

Desatenção e dispersão

Melhores resultados, nas avaliações orais, do que nas escritas; 
Dificuldade de coordenação motora fina;

Problema de lateralidade (confusão entre esquerda e direita,

ginástica);

Dificuldade de expressão: vocabulário pobre, frases curtas, estrutura simples; esquecimento de palavras;

Dificuldade de copiar as lições do quadro, ou de um livro;

Problema de conduta: retração, timidez, excessiva e depressão;

Desinteresse ou negação da necessidade de ler;

Leitura demorada, silabadas e com erros. Esquecimento de tudo o

que lê;

Salta linhas durante a leitura, acompanha a linha de leitura com o

dedo;

Demora demasiado tempo na realização dos trabalhos de casa;

Pode ser evidenciada uma capacidade acima da média em áreas como: desenho, pintura, música, teatro, esporte, entre outros.

De acordo com Leite (2012) é importante observar atentamente o modo como uma criança ler, pois, dessa forma pode apontar alguns indicadores de dislexia, como: o modo como a criança movimenta os lábios ou murmura ao ler; como movimenta a cabeça ao longo da linha; se é mais lenta ao ler oralmente do que na leitura silenciosa; se utiliza o dedo como recurso para não perder a linha do texto; se faz excessivas fixações do olho ao longo da linha impressa; se realiza excessivos retrocessos da vista ao ler.

Para observar os movimentos dos olhos da criança relatados como um dos sintomas da dislexia, o professor pode fazer a seguinte experiência: colocar um espelho sobre o lado oposto das páginas que a criança está lendo. Isso demostra algumas dificuldades relacionadas à dislexia auditivas ou visuais a qual Fonseca (1999), classifica como troca de fonemas (sons) e grafemas (letras) diferentes, por exemplo, trocando a palavra moto por "modo" ou "pato".

Conhecendo as causas das dificuldades, o potencial e as individualidades do indivíduo, o profissional pode utilizar a linha que achar mais conveniente. Os resultados irão aparecer de forma consistente e progressiva.

Ao contrário do que muitos pensam o disléxico sempre contorna suas dificuldades, encontrando uma alternativa. O mesmo responde bem a situações que possam ser associadas a vivências concretas e aos múltiplos sentidos. O disléxico também tem sua própria lógica, sendo muito importante o bom entrosamento entre profissional e paciente.

A criança disléxica tem a necessidade de aprender de forma diferenciada, no entanto, vale destacar que a dislexia não é uma doença, e sim uma dificuldade 
apresentada, que está relacionada à fala e escrita. Segundo Lima (apud ARAUJO e LUNA, 2005, p. 27) "Não há cura para a dislexia, mas o distúrbio pode ser tratado com a ajuda de fonoaudiólogos e psicoterapeutas." Dessa forma, existe tratamento e não medicamentos para esse distúrbio.

É necessário tratar essas crianças acometidas pela dislexia com atendimento prioritário com um especialista, este que da melhor forma possível possa orientar o professor e o estudante, dando-Ihes suportes pedagógicos para superar esse distúrbio. Além disso, vale deixar claro que quanto mais precoce o tratamento, melhores resultados serão obtidos.

\begin{abstract}
Existem trata mentos que estimulam o cérebro a relacionar letras em sons, o qual beneficia a apropriação ortográfica focalizando principalmente na reeducação da linguagem escrita. Nesse processo existem testes cognitivos que são realizados somente por psicólogos para traçar perfis cognitivos. A partir dos testes cognitivos, é solicitado o envolvimento de outros profissionais no tratamento da dislexia como: médicos de clinica geral, oftalmologistas/optrometristas, audiologistas, otorrinolaringologistas, terapeutas da linguagem e da fala, terapeutas ocupacionais, terapeutas da psicomotricidade e professores especializados na intervenção na dislexia. (LIMA, 2012)
\end{abstract}

No processo de tratamento da criança com dislexia é imprescindível além da equipe de especialista, o apoio dos familiares e uma instituição que possa dar suporte no processo da aprendizagem dessa criança. Sendo que a escolha da instituição escolar fundamental para superação desse quadro, pois, é de extrema importância que o educando seja tratado de maneira igualitária em relação aos demais colegas.

O docente pode utilizar metodologias para que o disléxico seja inserido em uma escola regular com o uso dos recursos visuais, pois as imagens podem proporcionar ao estudante disléxico uma nova perspectiva do assunto, pode também disponibilizar textos sobre alguns temas, criar esquemas de apresentar alguns temas. Além disso, pode gravar as aulas, considerando a dificuldade na leitura. Realizar atividades práticas, também é uma forma do disléxico aprender, produzidos e apresentados através de diferentes expressões e linguagens, com pesquisa, criatividade e experiências práticas, realizados em grupo ou de maneira individual.

É notório que o disléxico tem dificuldade para entender o que ler, para interpretar a mensagem, por isso, é imprescindível utilizar uma linguagem clara, 
objetiva, com termos conhecidos, elaborar enunciados com textos curtos, com linguagem objetiva, direta, tratar de um só assunto em cada questão, se for indispensável à utilização de um determinado texto subdividir o original em partes (não mais do que cinco ou seis linhas cada uma). Pode também recorrer a símbolos, sinais, gráficos, desenhos, modelos, esquemas e assemelhados, que possam fazer referência aos conceitos trabalhados. (CORREA, 2012)

Portanto, o tratamento quando criança é indispensável, já que caso contrário, essa vai para a vida adulta levando todas as dificuldades que não foram tratadas na infância, acarretando em diversos problemas no meio em que está inserido com na carreira profissional e acadêmica.

Segundo Correa (2012):

A nível de aprendizagem, os especialistas recomendam uma atenção individualizada em que se respeite 0 ritmo de aprendizagem da criança e em que se evite a aprendizagem pelo erro. Há pequenas alterações fáceis de superar, mas também há dificuldades que se podem manter por toda a vida. A dislexia impõe um diagnóstico diferencial, feito por especialistas nesta área, até porque há problemas de leitura e escrita que nada têm a ver com dislexia.

Uma das principais dificuldades no diagnóstico e tratamento dos disléxicos é a ausência dos familiares no processo. Portanto, é de grande importância presença da família para ajudar no diagnóstico e tratamento, visto que, a partir das observações feitas pela família é possível realizar um tratamento melhor, que permita à criança um desenvolvimento pleno, ao nível educacional e social.

O melhor que os pais podem fazer é aceitar a situação, procurar ajuda e ter paciência. Além disso, é importante mostrar à criança que ela não é burra nem preguiçosa, mas que enfrenta uma condição um pouco diferente e que tem tratamento. Ao perceber isso, ela ficará aliviada ao perceber que essa situação tem solução. É fundamental que seu filho conte com a aceitação e o suporte da família, para que consiga superar suas dificuldades. (MALUF, 2009)

A família deve ter atenção e observar o processo de aprendizagem da criança, e assim que desconfiar de qualquer dificuldade buscar ajuda de um profissional para ajudar a identificar e se necessário tratar. Pois, quando há acompanhamento dos familiares, as dificuldades são reduzidas no processo de aprendizagem. Deste modo, é necessário atenção dos pais nesse contexto para 
identificar os sinais que a criança realmente apresenta em relação a dificuldade de aprendizagem, e que dê apoio nesse momento incentivando e motivando, e não veja a criança como preguiçoso, com mal comportada ou que não gosta de estudar.

\section{CONSIDERAÇÕES FINAIS}

Dentro do que foi abordado é possível inferir que primeiramente a dislexia precisa ser identificada para que haja o desenvolvimento da criança com esse tipo de distúrbio. A escola, os professores e os familiares podem colaborar muito na prevenção das dificuldades de aprendizagem dos estudantes portador da dislexia, assim como de outras dificuldades.

Após o diagnóstico, é indispensável que o professor entenda e compreenda a dislexia para superar as dificuldades enfrentadas pelo estudante. Embora ciente que muitos professores não têm clareza acerca do significado da dislexia, muitas vezes relacionando com o desinteresse em aprender, desatenção, falta de concentração, dentre outros. É iminente a capacitação desses docentes para que possam notar um aluno com dislexia e saber trabalhar com esse tipo de distúrbio. Dessa forma, o professor sabendo trabalhar com o estudante disléxico, poderá utilizar metodologias que facilitem o processo de ensino e aprendizagem, estimulando e motivando este para estudar.

Através das discussões nesse estudo relacionadas a essa dificuldade de aprendizagem, pode-se perceber que essa é uma questão desafiadora e preocupante para a sociedade, pois, a criança muitas vezes sofre pela falta de conhecimento e preparo dos familiares e profissionais.

Foi possível perceber também que existe tratamento para essa dificuldade de aprendizagem, no entanto, vai depender dos esforços dos familiares e acompanhamento profissional como psicólogo e fonoaudiólogo para orientar o professor, pais e estudantes. Uma vez que, a criança necessita aprender de forma diferenciada e para isso precisa de métodos apropriados para que esta parceria acarrete em resultados positivos.

Sabe-se que a dificuldade na educação brasileira é grande, pois, os docentes enfrentam muitas dificuldades como salas de aulas lotadas, falta de acompanhamento dos pais, escassez de recursos, de profissionais na área de 
fonoaudiologia, psicologia, psicopedagogia, dentre outros especialistas, carga horária elevadas dos docentes, dentre outros. Sendo assim, são necessários muitos esforços para conseguir alcançar os objetivos de planejar aulas para modificar a metodologia e assim atender os alunos, além de realizar tratamento sem apoio dos familiares e sem recursos.

Com a realização desse trabalho foi possível refletir sobre o conceito, características, causas, diagnóstico e tratamento da dislexia. Apesar de vários estudos discutirem sobre o tema, ainda há muito o que ser descoberto sobre esse distúrbio. Sendo que a escola também tem muito que avançar na metodologia voltada para atender essa necessidade educacional, através da produção de recursos e materiais didáticos específicos, na formação inicial e continuada dos docentes, acolhendo o educando para que supere as dificuldades de aprendizagem e evite o fracasso na escola.

\section{REFERÊNCIAS}

ALMEIDA, D. Como Lidar com a Dislexia na Escola. 2010. Disponível em: <http://www.webartigos.com/artigos/como-lidar-com-a-dislexia-na-escola/37938/>. Acesso em: 21 mar. 2017.

ARAUJO, G. M. L. de; LUNA, M. J. de. M. (ORGS). Formação em Lingua Portuguesa - Novas experiencias. Recife: Editora Universitaria UFPE, 2005.

CAPOVILLA, A. G. S. \& CAPOVILLA, F. C. Problemas de leitura e escrita: Como identificar, prevenir e remediar numa abordagem fônica. 2000. São Paulo: Memnon.

CORREA, V. A Dislexia: Problemas e Intervenções Durante o Processo de Alfabetização. Niterói, 2012.

CRITCHLEY, M. The dyslexic Child. 1970, London: Springfield Thomas.

FONSECA, V. Aprender a Aprender - A Educabilidade Cognitiva. 1999, Notícias Editorial.

HOUTE, A. V.; ESTIENNE, F. Dislexias. Porto Alegre: Artmed, 2001.

IANHEZ, M. E.; NICO, M. Â. Nem sempre é o que parece: como enfrentar a dislexia e os fracassos escolares. São Paulo: Elsevier, 2002.

LEITE, V. A. M. Dimensões da Não-Aprendizagem. Ed. ver. - Curitiba, PR: IESDE Brasil, 2012. 
LIMA, I. G. S. A Dislexia e o Contexto Escolar. Anhanguera Educacional. Vol. V, $N^{\circ}$. N, Ano 2012 - p. 1-15. Disponível em: <http://www.pixfolio.com.br/arq/1401825967.pdf> Acesso em: 20 mar. 2017.

MALUF, M. I. Afinal o que é dislexia? Disponível em:<HTTP//www.partes.com.br/ educação/dislexia.asp>. Acesso em 09 abr. 2017.

MOOJEN, S. M. P. O papel do Fonoaudiólogo/Psicopedagogo e da Escola na Dislexia. Disponível em: <http://www.andislexia.org.br/artigo-AND-3>. Acesso em: 07/04/2017.

MOURA, S. P. P. T. de. A dislexia e os desafios pedagógicos. Universidade Cândido Mendes. Niterói: RJ. 2013. Disponível em: $<$ http://www.avm.edu.br/docpdf/monografias_publicadas/N205864.pdf>. Acesso em: 01/04/2017.

NUNES, T.; BUARQUE, L.; BRYANT, P. Dificuldades na Aprendizagem da leitura: teoria e prática. 5a Ed. São Paulo: Cortez, 2003.

PENNINGTON, B. F. Diagnósticos de distúrbio de aprendizagem. São Paulo: ed., Pioneira Thompsaon Learning, 1997. p. 65.

TOPCZEWSKI, A. Aprendizado e suas desabilidades: como lidar? São Paulo: Casa do Psicólogo, 2000.

TELES, P. Dislexia: Método Fonomímico - Abecedário e Silabário. 2009, Lisboa: Distema.

TELES, P. Como identificar? Como intervir? In: Revista portuguesa de Clinica Geral. 2004.

ZORZI, J. L. Guia prático para ajudar crianças com dificuldade de aprendizagem: dislexia e outros disturbios. Um manual de boas e saudaveis atitudes. Pinhais: Editora Melo, 2008. 